\title{
Graphene-Multiwalled Carbon Nanotube Hybrids Synthesized by Gamma Radiations: Application as a Glucose Sensor
}

\author{
Leila Shahriary, ${ }^{1,2}$ Hedayatollah Ghourchian, ${ }^{2}$ and Anjali A. Athawale ${ }^{1}$ \\ ${ }^{1}$ Department of Chemistry, University of Pune, Ganeshkhind, Pune 411007, India \\ ${ }^{2}$ Department of Biophysics, Institute of Biochemistry and Biophysics, University of Tehran, Tehran 1417614411, Iran \\ Correspondence should be addressed to Anjali A. Athawale; agbed@chem.unipune.ac.in
}

Received 20 January 2014; Accepted 5 May 2014; Published 1 June 2014

Academic Editor: Thomas Thundat

Copyright (c) 2014 Leila Shahriary et al. This is an open access article distributed under the Creative Commons Attribution License, which permits unrestricted use, distribution, and reproduction in any medium, provided the original work is properly cited.

\begin{abstract}
Three-dimensional hybrid nanomaterial of graphene-multiwalled carbon nanotubes (G-MWCNTs) was synthesized using gamma rays emitted by a ${ }^{60} \mathrm{Co}$ source with a dose rate of $3.95 \mathrm{~Gy} \mathrm{~min}^{-1}$. The products were characterized by fourier transform infrared (FTIR), ultraviolet-visible (UV-Vis), photoluminescence (PL), and micro-Raman spectroscopy, X-ray diffraction analysis (XRD), scanning electron microscopy (SEM), and transmission electron microscopy (TEM). FTIR and UV-Vis analysis reveals the formation of hybrid nanomaterial which is confirmed by XRD, micro-Raman analysis, and PL. SEM micrograph depicts the composite structure of graphene layers and MWCNTs, while the TEM micrograph exhibits graphene layers covered by MWCNTs. The G-MWCNTs hybrid used as electrode for electrochemical studies in $\mathrm{K}_{3} \mathrm{Fe}(\mathrm{CN})_{6}$ shows enhancement in electrocatalytic behavior, compared to each individual starting material, therefore, has been applied for amperometric sensing of glucose in alkaline solution and exhibits sensitivity of $12.5 \mu \mathrm{AmM}^{-1} \mathrm{~cm}^{-2}$ and low detection limit $1.45 \mu \mathrm{M}(S / N=3)$ in a linear range of 0.1 to $14 \mathrm{mM}$ $\left(R^{2}=0.985\right)$.
\end{abstract}

\section{Introduction}

Carbon is one of the most abundant elements found in nature existing in various allotropic forms. It has four electrons in its outer valence shell and is a conducting in nature. In the last two decades, novel nanostructures have emerged such as fullerenes, carbon nanotubes, and graphene. The flat monolayer of $\mathrm{sp}^{2}$ carbon atoms tightly packed in twodimensional honeycomb-like lattice is the building block for graphene. Due to its remarkable mechanical, optical, thermal, electronic, and magnetic [1-5] properties it has been used in various areas of nanosize research such as electronics, batteries, fuel cells, super capacitors, sensors, and biosensors [6-11]. Compared to carbon nanotubes, graphene exhibits potential advantages of high surface area, ease of processing, low cost, safety [12], and high purity (absence of transition metals, $\mathrm{Fe}, \mathrm{Ni}$, etc.) [13]. Thus, it provides a good platform to study the electrocatalytic effects of carbon materials. In fact, graphene oxide (GO) sheets are rich in oxygencontaining functional groups such as alkoxy, hydroxyl, and carboxyl groups $[14,15]$ and, hence, can be well dispersed in polar solvents. However, the formation of reduced GO in aqueous solution results in aggregation of sheets due to hydrophobic nature and induces strong $\pi-\pi$ interactions when the oxygen-containing functional groups are removed during the reduction process [16]. Important drawbacks in the synthesis of graphene are difficulty in isolating single layer and its tendency to curl, fold, and corrugate due to the flexibility of sheets [17]. The large folds arise during processing [18], whereas smaller ripples tend to be inherent in the structure of isolated layers [19]. As a result, graphene shows lower surface area and conductivity compared to the predicted theoretical value. Hence, preparation of individual graphene sheets is rather critical. On the other hand, carbon nanotubes (CNTs), consisting of cylindrical graphene sheets with nanometer diameter, have high mechanical strength and chemical stability, good electrical conductivity, rich optical properties, and high surface area. Therefore, CNTs constitute important materials as well as electrodes for sensing applications [20]. Electrical conductivity of CNTs is also affected 
due to the nonuniform contact and discontinuities between all the CNTs in the heterogeneous structure [21], thereby limiting their application as sensors [17, 22-24]. Therefore, an intelligent and unique graphene-carbon nanotube hybrid film, consisting of CNTs connected perpendicularly to graphene layers, could overcome some of the shortcomings and limitations of individual components [25-29]. Thus, many efforts have been made so as to obtain graphene-carbon nanotube hybrids by different methods of synthesis [25-32].

Gamma $(\gamma)$ radiations have been used for many years as a competitive method to develop new materials, metal nanoparticles, and their composites [33-35]. Advantages of this technique over the other methods are self-generation of reducing agent, avoiding the use of toxic reducing agents such as hydrazine, simultaneous control of ion reduction and suppression of undesired oxidation products [33], formation of products under ambient conditions, simplicity, and economic.

In the present paper, an efficient, highly reproducible, and clean route towards synthesis of three-dimensional graphenemultiwalled carbon nanotube (G-MWCNT) hybrids has been reported. The hybridization of GO and acid functional multiwalled carbon nanotubes (f-MWCNTs) was carried out by $\gamma$-ray irradiation of the deoxygenated mixture of GO and MWCNTs in alcohol-water solution (Figure 1). Probable mechanism involving the formation of hybrid has been proposed. The differences observed in the resistance of the hybrid nanomaterials indicate that GO: MWCNTs ratio can further be optimized to improve the interface and nanostructures. Additionally, the electrocatalytic behavior of G-MWCNTs hybrids with different ratios of GO and MWCNTs has been examined. The G-MWCNTs hybrids show an improvement in electrocatalytic properties in comparison to each of the individual starting materials. The highest activity is observed for $1: 1$ hybrid G-MWCNTs. Increase in ratio to $1: 3$ does not show significant difference. Therefore, performance of $1: 1 \mathrm{G}$ MWCNTs hybrid has been investigated as an amperometric glucose sensor.

\section{Experimental}

2.1. Materials. Extra pure graphite powder and MWCNTs (carbon purity: min. 95\%, number of walls: 3-15, outer diameter: 5-20 nm, inner diameter: 2-6 nm, and length: 1$10 \mu \mathrm{m})$ were supplied by LOBA-Chemie and Reinste Nano Ventures Pvt. Ltd. (Delhi, India), respectively. Concentrated sulphuric acid and $30 \%$ hydrogen peroxide $\left(\mathrm{H}_{2} \mathrm{O}_{2}\right)$ solution were from Qualigens (India). Alcohols (methanol, ethanol, isopropanol, and tert-butyl alcohol), $\mathrm{KMnO}_{4}$, concentrated $\mathrm{HCl}$, and $\mathrm{HNO}_{3}$ were obtained from SD-Fine Chemical (SDFCL) (India). Sodium nitrate was purchased from SigmaAldrich (USA).

2.2. Instrument. The ${ }^{60} \mathrm{Co} \gamma$-source was from the Department of Chemistry, University of Pune, supplied by BARC (Bhabha Atomic Research Center), Mumbai, India, with a dose rate of $3.95 \mathrm{~Gy} \mathrm{~min}^{-1}$. The solutions were sonicated using a sonicator supplied by IMECO, India ( $34 \mathrm{KHz}$ frequency, $500 \mathrm{~W}$ ).
Voltammetric measurements were performed on a Potentiostat/Galvanostat (model 263-A, EG\&G USA) controlled by power suite software package and GPIB interface, in a conventional three-electrode system, together with a $\mathrm{Pt}$ loop as counter and $\mathrm{Ag} / \mathrm{AgCl}$ (saturated $\mathrm{KCl}$ ), as a reference electrode. Bare glassy carbon (GC) and GC modified with $\mathrm{GO},-\mathrm{COOH}$ functionalized multiwall carbon nanotubes ( $\mathrm{f}$ MWCNTs), and G-MWCNT hybrids electrodes were used as working electrodes. All measurements were performed in air atmosphere and room temperature. Prior to experiments, GC electrodes were polished with 0.3 and $0.05 \mu \mathrm{m}$ alumina and rinsed with copious amount of Milli-Q water.

2.3. Synthesis of GO. GO was synthesized from graphite powder using modified Hummer's method [36]. In brief, $1 \mathrm{~g}$ of graphite and $0.5 \mathrm{~g}$ of sodium nitrate were added in $23 \mathrm{~mL}$ of concentrated sulphuric acid under constant stirring. $\mathrm{KMnO}_{4}(3 \mathrm{~g})$ was added gradually to the above solution while keeping the temperature less than $20^{\circ} \mathrm{C}$ to prevent overheating and explosion. The mixture was stirred at $35^{\circ} \mathrm{C}$ for $1 \mathrm{~h}$ and the resulting solution was diluted by adding $500 \mathrm{~mL}$ of double distilled water under vigorous stirring. To ensure the completion of reaction with $\mathrm{KMnO}_{4}$, the suspension was further treated with $30 \% \mathrm{H}_{2} \mathrm{O}_{2}$ solution ( $5 \mathrm{~mL}$ ). The graphene oxide sheets thus obtained were washed with $\mathrm{HCl}$ and $\mathrm{H}_{2} \mathrm{O}$, followed by filtration and drying.

2.4. Synthesis of $f$-MWCNTs. f-MWCNTs (functionalized with $\mathrm{COOH}$ groups) were synthesized by refluxing purified MWCNTs in concentrated $\mathrm{HNO}_{3}$ (ca. $15.8 \mathrm{M}$ ) for $8 \mathrm{~h}$.

2.5. Synthesis of G-MWCNT Hybrids. G-MWCNT hybrids were prepared by $\gamma$-irradiation method with three different weight ratios of $3: 1,1: 1$, and $1: 3$ (ratio of GO to MWCNTs). Initially, appropriate amount of GO was dispersed in Milli$\mathrm{Q}$ water $\left(1 \mathrm{mg} \mathrm{mL}^{-1}\right.$ of solid) by sonication ( $\left.1 \mathrm{~h}\right)$ followed by addition of $\mathrm{f}-\mathrm{MWCNT}$ and alcohol (methanol, ethanol, isopropanol, or tert-butanol); the mixture was further sonicated for $30 \mathrm{~min}$. The homogenous suspension was transferred into a glass bottle fitted with a septum, bubbled with nitrogen gas for $10 \mathrm{~min}$ to remove the dissolved oxygen, and then irradiated at room temperature for different time intervals ( $12 \mathrm{~h}-60 \mathrm{~h}$, the corresponding doses being 2.84, 5.70, 11.38, and $14.22 \mathrm{kGy}$, resp.) at a dose rate of $3.95 \mathrm{~Gy} \mathrm{~min}^{-1}$. The product thus obtained was collected, washed with Milli$\mathrm{Q}\left(18 \mathrm{M} \Omega \mathrm{cm}^{-1}\right)$ water, and dried under vacuum. UV-Vis spectra of samples (S1) indicated significant effect on the extent of reduction of GO + f-MWCNTs; the best conversion was observed for a total dose of $11.38 \mathrm{kGy}$, and hence further experiments were carried out at a dose of $11.38 \mathrm{kGy}$. Results for f-MWCNTs, GO, and GO + f-MWCNTs $(1: 1)$ irradiated at $11.38 \mathrm{kGy}$ in ethanol/water solution are discussed in detail with other systems included wherever necessary.

2.6. Preparation of Modified GC Electrodes. GC electrode (3.0 mm diameter) was polished with 0.3 and $0.05 \mu \mathrm{m}$ alumina slurries to obtain a mirror-like surface and rinsed with Milli-Q water and dried. Fresh dispersions of GO, 


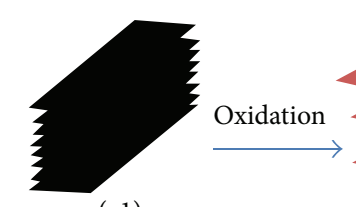

(a1)

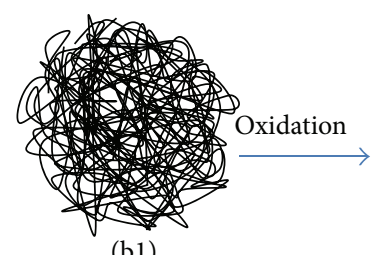

(b1)

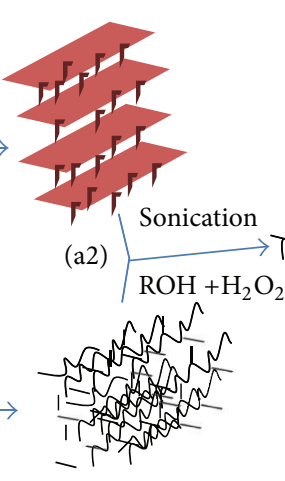

(b2)
(a1) Graphite
(b1) MWCNTs
(a2) GO
(b2) f-MWCNTs
$((\mathrm{a} 2)+(\mathrm{b} 2)) \mathrm{GO}+\mathrm{f}-\mathrm{MWCNTs}$
(c) G-MWCNTs
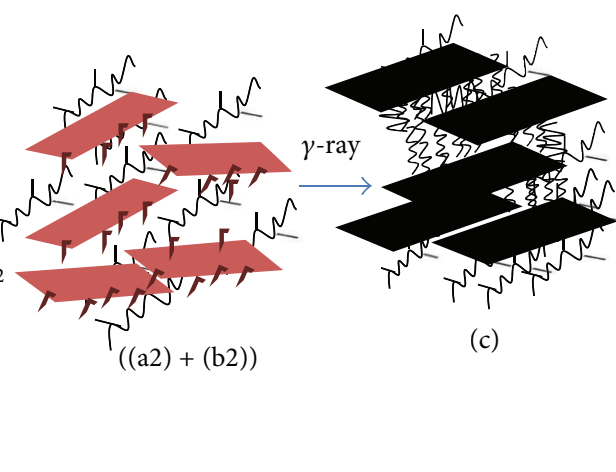

(c)

FIGURE 1: Schematic illustration for preparation of G-MWCNTs hybrid.

f-MWCNTs, and G-MWCNTs were prepared by adding $1.0 \mathrm{mg}$ of sample in $1.0 \mathrm{~mL}$ of Milli-Q water followed by sonication. From this, $10 \mu \mathrm{L}$ of solution was drop-casted on the precleaned GC disk electrode and dried under vacuum at room temperature to obtain modified GC electrodes. Bare GC and modified electrodes were used for electrochemical measurements.

2.7. Characterization Techniques. Fourier transform infrared (FTIR) spectra of all the samples were recorded on a FTIR spectrophotometer (Thermo Scientific NICOLET 6700) using $\mathrm{KBr}$ as the mulling agent. Ultra violet-visible (UVVis) and photoluminescence (PL) spectra of the samples were obtained on a UV-Vis spectrophotometer (PerkinElmer LAMBDA 950) and spectrofluorometer (JASCO, FP8300), respectively. X-ray diffraction (XRD) analysis of powders was carried out on a Bruker AXSD-8 advance X-ray diffractometer with monochromatic $\mathrm{CuK}_{\alpha}$ radiation $(\lambda=1.5406 \AA)$. Data were collected from $10^{\circ}$ to $60^{\circ}$ at a scan rate of $0.1^{\circ} \mathrm{min}^{-1}$. The morphologies of the samples were observed under scanning electron microscope (SEM, JEOL JSM-6360) and transmission electron microscope (TEM, TECNAT G2 20ULTRA-TWIN, FEI instrument). Suspensions of the samples in Milli-Q water were loaded on grids of 200 mesh size. Micro-Raman spectra of the samples were recorded by using HORIBA Jobin Yvon (France Instrument), at $532 \mathrm{~nm}$ laser power $1.7 \mathrm{~mW}, 100 \mathrm{x}$ objective lens and 0.9 NA. HAMEG programmable LCR-Bridge hm8118 was used to measure the resistance of the samples. For measurement of resistance, pellets of the samples $\left(1 \mathrm{~cm}^{2}\right.$ and $500 \mu \mathrm{m}$ in thickness $)$ were prepared by placing $50 \mathrm{mg}$ of each powder between two iron plates of a die and compressed at a pressure of $78 \mathrm{KN}$.

\section{Results and Discussion}

3.1. Spectroscopic Characterization. The FTIR spectra of GO, f-MWCNTs, GO + f-MWCNTs (physical mixture), and GMWCNTs are given in Figure 2(a). Spectrum of GO exhibits peaks at 1622,1730 , and $1035 \mathrm{~cm}^{-1}$ corresponding to $\mathrm{C}=\mathrm{C}$, $\mathrm{C}=\mathrm{O}$, and $\mathrm{C}-\mathrm{O}$ stretching, respectively. Also, the broad band at $3340 \mathrm{~cm}^{-1}$ is attributed to $\mathrm{O}-\mathrm{H}$ stretching mode of intercalated water [15]. On the other hand, spectrum related to f-MWCNTs (Figure 2(a)) shows two strong peaks at 3500 and $1710 \mathrm{~cm}^{-1}$ representing $\mathrm{O}-\mathrm{H}$ and $\mathrm{C}=\mathrm{O}$ stretching, respectively. The spectrum of $\mathrm{GO}+\mathrm{f}-\mathrm{MWCNTs}$ exhibits bands similar as for GO, while, in the case of G-MWCNTs hybrid material (Figure 2(a)), the characteristic absorption bands of GO, f-MWCNTs, and GO + f-MWCNTs [37] are suppressed drastically. However, two new peaks are observed at $\sim 1450$ and $\sim 1580 \mathrm{~cm}^{-1}$ that can be attributed to the $\mathrm{C}=\mathrm{C}$ stretching of aromatic ring indicating the formation of $\mathrm{G}$ MWCNTs hybrid.

These results were further confirmed by UV-Vis analysis of the samples (Figure 2(b)). The peak observed for GO at $230 \mathrm{~nm}$ (spectrum (A)) represents the $\pi-\pi^{*}$ transitions of C$\mathrm{C}$ aromatic ring, while the shoulder at $308 \mathrm{~nm}$ corresponds to $n-\pi^{*}$ transition of $\mathrm{C}=\mathrm{O}$ bond $[38,39]$. In case of $\mathrm{f}-\mathrm{MWCNTs}$ the absorption peak observed at $\sim 260 \mathrm{~nm}$ (spectrum (B)) is attributable to the $\pi-\pi^{*}$ transitions of $\mathrm{f}-\mathrm{MWCNTs}[40,41]$. However, the spectrum of G-MWCNTs hybrid (spectrum (C)) shows distinctly different nature compared to GO or f-MWCNTs. This spectrum consists of four peaks at 208, 225,275 , and $281 \mathrm{~nm}$. To understand the origin of these new peaks, UV-Vis spectrum of unirradiated solution of GO + f-MWCNTs (physical mixture in ethanol-water, Figure 2(b) spectrum (D)) and irradiated samples of GO (spectrum (E)) and f-MWCNTs (spectrum (F)) were recorded. From the results, it is observed that, in case of physical mixture, the spectrum shows the features similar to GO. On the contrary, GO after irradiation exhibits a peak at $275 \mathrm{~nm}$, while $\mathrm{f}$ MWCNTs show peaks at 208, 225, and $281 \mathrm{~nm}$. These results justify the formation of hybrid after irradiation (spectrum (C)). The considerable red shift in peaks (230 to 275 for GO and 260 to 281 for f-MWCNTs) in the hybrid sample is due to increase in electron density and structural ordering consistent with the restoration of $\mathrm{sp}^{2}$ carbon atoms $[29,32]$. 


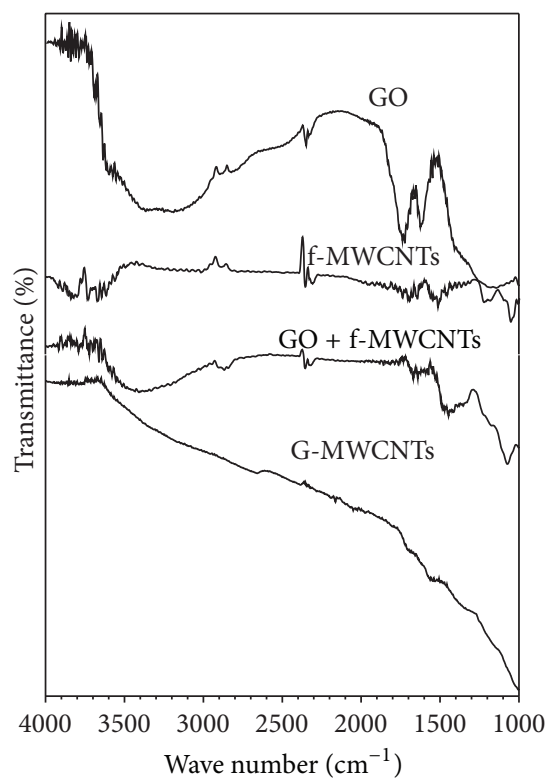

(a)

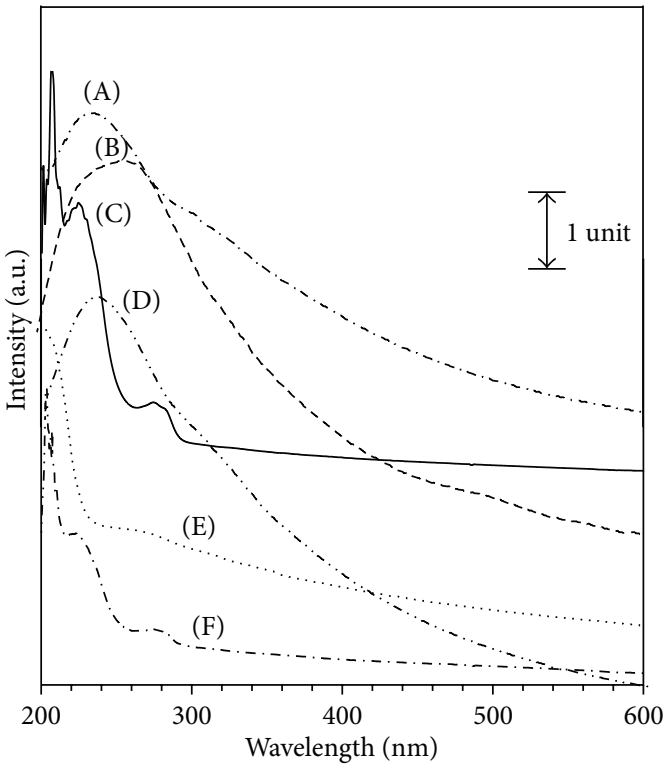

(b)

Figure 2: (a) FTIR spectra of GO, F-MWCNTs, GO + f-MWCNTs and G-MWCNTs (top to bottom). (b) UV-Vis spectra of GO (A), fMWCNTs (B), G-MWCNTs (C), GO + f-MWCNTs before $\gamma$-ray irradiation (D), GO (E), and f-MWCNTs (F) after $\gamma$-ray irradiation.

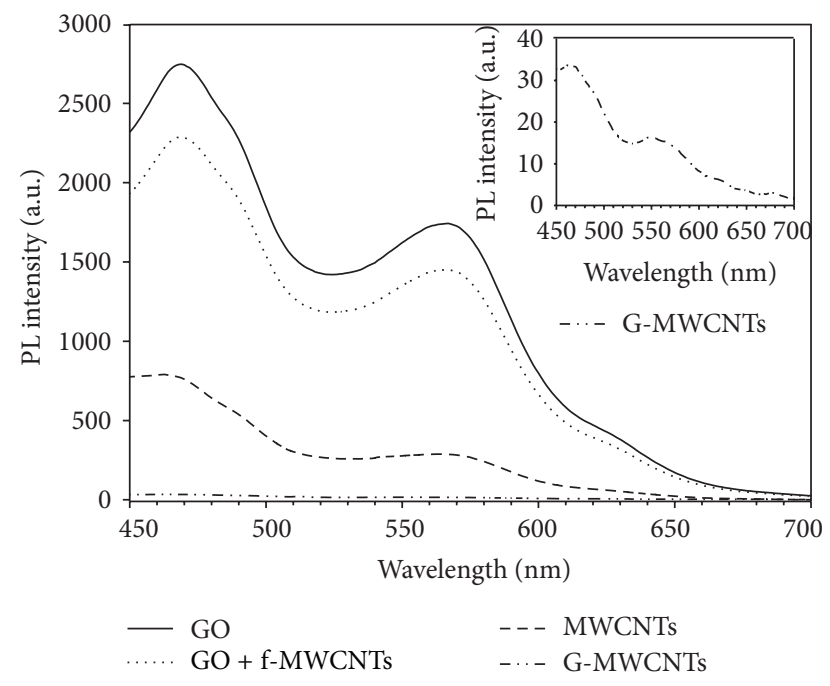

Figure 3: PL spectra of GO (solid line), GO + f-MWCNTs (dotted line), f-MWCNTs (dashed line), and G-MWCNTs (dotted-dashed line with inset depicting the drastic decrease in intensity). The excitation wavelength was $240 \mathrm{~nm}$.

Further, the red shift confirms the $\pi-\pi$ stacking interactions between the aromatic basal planes of GO and MWCNTs. Apart from this, the new peaks at 208 and $225 \mathrm{~nm}$ can be attributed to the formation of $\mathrm{C}-\mathrm{H}$ bonds simultaneous to $\mathrm{C}-$ C bond breaking [42].

To verify whether the GO nanosheets are electronically coupled to the MWCNTs instead of physical attachment, the photoluminescence (PL) spectra of GO, f-MWCNTs, $\mathrm{GO}+\mathrm{f}-\mathrm{MWCNTs}$, and G-MWCNTs were obtained at an excitation wavelength of $240 \mathrm{~nm}$ and the results are compared in Figure 3. As seen from the figure, the PL spectrum of $\mathrm{GO}$ and GO + f-MWCNTs (Figure 3, solid and dotted line) exhibits a strong peak at $\sim 470 \mathrm{~nm}$ that can be correlated to the $\pi-\pi^{*}$ transition of GO. The origin of a sharp emission peak at $\sim 567 \mathrm{~nm}$ can be ascribed to the $\mathrm{C}-\mathrm{O}, \mathrm{C}=\mathrm{O}$, and $\mathrm{O}=\mathrm{C}-\mathrm{OH}$ functionalized groups [43].

Similarly, intense emission is observed for f-MWCNTs (Figure 3 dashed line) [44]. On the other hand, in case of GMWCNTs hybrid significant quenching of the PL spectrum is observed (Figure 3, dashed-dotted line and inset) which could be due to the following reasons: (i) the emission from graphene being quenched due to absorption of electrons by MWCNTs (excellent electron acceptors) [32], (ii) removal of functional groups from GO and f-MWCNTs after irradiation, and (iii) formation of new $\mathrm{sp}^{2}$ clusters [43] resulting in the blue shift observed in the spectrum (470 nm in GO to $466 \mathrm{~nm}$ in G-MWCNTs hybrid).

3.2. Crystallographic and Structural Analysis. The X-ray diffractograms of GO (A), GO + f-MWCNTs (B), f-MWCNTs (C), and G-MWCNTs hybrid (D) are displayed in Figure 4(a). As observed from the figure, GO and GO + f-MWCNTs (Figures 4(A) and 4(B)) show a single peak at $11.36^{\circ}$ (dspacing $0.767 \mathrm{~nm}$ ) and f-MWCNTs (Figure $4(\mathrm{C})$ ) exhibit two peaks at $26.13^{\circ}$ (d-spacing: $0.339 \mathrm{~nm}$ ) and $43.48^{\circ}$ (dspacing $0.206 \mathrm{~nm}$ ), while, in case of G-MWCNTs hybrid (Figure $4(\mathrm{D})$ ), four peaks are observed at $11.17^{\circ}, 12.21^{\circ}, 25.80^{\circ}$, and $42.621^{\circ}$ (d-spacing $0.790,0.724,0.840$, and $0.210 \mathrm{~nm}$, resp.) indicating the presence of both constituents.

Presence of four peaks in the hybrid with slight shift with reference to those observed in individual substances together with slight increase in d-spacing confirms the formation of 


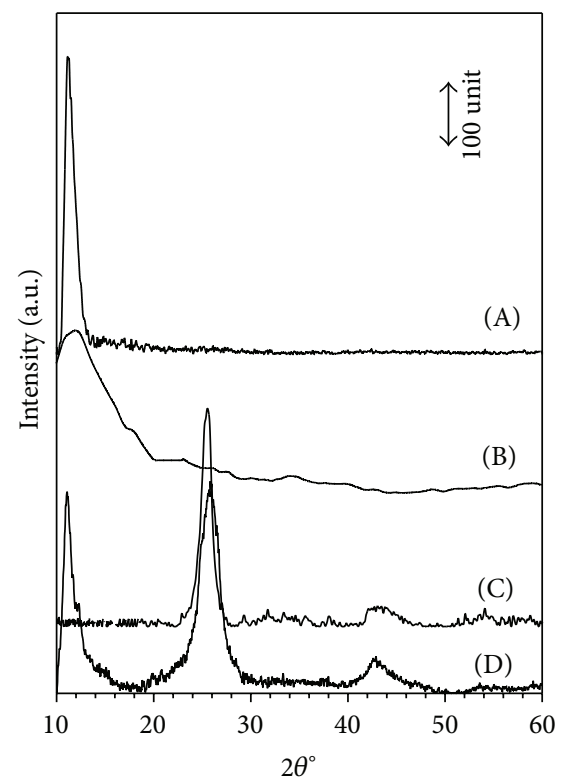

(a)

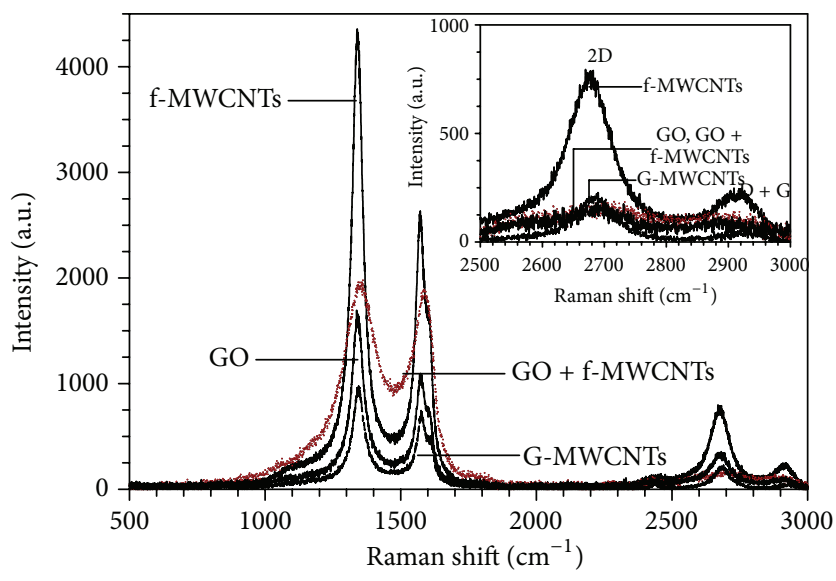

(b)

Figure 4: (a) X-ray diffractograms of GO (A), GO + f-MWCNTs (B), f-MWCNTs (C), and G-MWCNTs (D). (b) Raman spectra of fMWCNTs, GO + f-MWCNTs, GO, and G-MWCNTs, from the top to the bottom, respectively; (b) inset shows the Raman spectra at an expanded scale to manifest the $2 \mathrm{D}$ and $\mathrm{D}+\mathrm{G}$ bands.

new structure. It has been reported that, after irradiation and removal of oxygen-containing functional groups, graphene oxide shrinks and the interlayer spacing decreases [45]. However, in the present reaction, at the time of reduction (during irradiation) MWCNTs are introduced between the graphene layers, and they avoid stacking up of graphene layers, therefore interlayer spacing does not show significant changes. It is worth noting that the data for GO and fMWCNTs are in good agreement with the previous reports $[28,46]$. The electronic and crystallographic structures of the samples were evaluated by micro-Raman spectroscopy. The Raman spectra of carbon materials show three wellknown peaks called D, G, and $2 \mathrm{D}$ observed at $\sim 1340, \sim 1540$, and $\sim 2650 \mathrm{~cm}^{-1}$, respectively. The $\mathrm{G}$ peak corresponds to the optical $\mathrm{E}_{2 \mathrm{~g}}$ phonons at the Brillouin zone center and represents the bond stretching of $\mathrm{sp}^{2}$ carbon pairs in both rings and chains. The $\mathrm{D}$ peak corresponds to the breathing mode of $\mathrm{sp}^{2}$ atoms in aromatic rings indicating the presence of defects [31, 47] and 2D band corresponds to second-order dispersion, a characteristic feature of two-phonon double resonance process. Figure 4(b) illustrates the typical microRaman spectra of f-MWCNTs, GO, GO + f-MWCNTs, and G-MWCNTs samples obtained at an excitation wavelength of $532 \mathrm{~nm}$. Three distinct peaks are observed in each sample corresponding to $\mathrm{D}$ band, $\mathrm{G}$ band, and 2D band, respectively, as mentioned earlier. In the Raman spectra the $D / G$ and $2 \mathrm{D} / \mathrm{D}+\mathrm{G}$ intensity ratios $\left(I_{\mathrm{D}} / I_{\mathrm{G}}\right.$ and $\left.I_{2 \mathrm{D}} / I_{\mathrm{D}+\mathrm{G}}\right)$ are usually used to evaluate the average size of crystalline $\mathrm{sp}^{2}$ domains and defect densities in graphene sheets [32]. However, the $I_{\mathrm{D}} / I_{\mathrm{G}}$ and $I_{2 \mathrm{D}} / I_{\mathrm{D}+\mathrm{G}}$ ratios of G-MWCNTs hybrid (1.30 and 4.10 , resp.) are remarkably greater than those of GO (1.03 and
1.62) and GO + f-MWCNTs (1.06 and 1.62) indicating higher degree of topological disorder and defect density together with higher degree of crystallinity within G-MWCNTs hybrid material in which a larger number of smaller sized graphitic demines are present in new hybrid materials. Also, the width of D and 2D bands for G-MWCNTs (Figure 4(b) inset) is narrower than that of the starting materials (GO and $f-$ MWCNTs) [48]. These results indicate the presence of defects caused by irradiation in G-MWCNTs hybrid material which leads to an improved electron transfer as confirmed from the electrochemical measurement discussed in Section 3.5.

Further, on radiolysis of water, $\gamma$-ray irradiation decomposes water molecules to both oxidative $\left({ }^{\circ} \mathrm{OH}\right)$ and reductive $\left(\mathrm{H}^{\bullet}\right.$ and $\left.\mathrm{e}^{-}\right)$species (1), whereas alcohols act as ${ }^{\circ} \mathrm{OH}$ radical scavengers and thereby convert into reducing radicals (2) which provides a reducing medium for chemical reaction to occur under $\gamma$-ray irradiation in the absence of oxygen (oxygen support formation of strong oxidative products such as $\mathrm{H}_{2} \mathrm{O}_{2}$ and ${ }^{\circ} \mathrm{O}_{2} \mathrm{H}$ and $\mathrm{O}_{2}^{-}$) [49]:

$$
\begin{gathered}
\mathrm{H}_{2} \mathrm{O} \stackrel{\gamma \text {-irradiation }}{\longrightarrow} \mathrm{e}_{\mathrm{aq}}^{-}+\mathrm{H}^{\bullet}+{ }^{\bullet} \mathrm{OH} \\
\mathrm{ROH}+{ }^{\cdot} \mathrm{OH}\left({ }^{\bullet} \mathrm{H}\right) \longrightarrow \mathrm{H}_{2} \mathrm{O}\left(\mathrm{H}_{2}\right)+\mathrm{R}^{\bullet}
\end{gathered}
$$

where RH corresponds to methanol, ethanol, isopropanol, and tert-butanol. However, to study the effect of different alcohol structures on the $\gamma$-ray irradiation reaction, a variety of alcohols (methanol, ethanol, isopropanol, and tertbutanol) with $1: 1(\mathrm{~V} / \mathrm{V})$ ratio with water as a solvent medium were tested. The results revealed that ethanol is the most effective in this reaction system $(\mathrm{S} 2, \mathrm{~S} 3)$. This can be related 


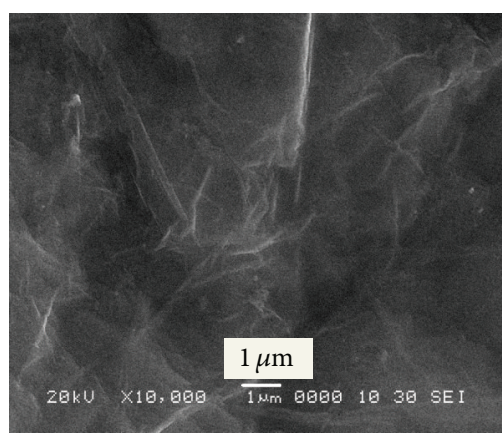

(a)

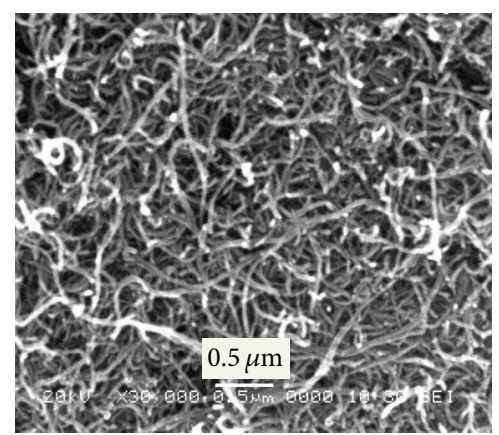

(b)

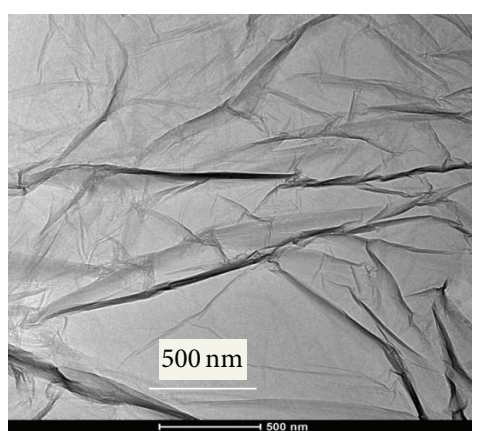

(c)

FIGURE 5: SEM micrographs of (a) GO, (b) MWCNTs, and (c) TEM micrograph of GO.

to the differences in the rate constants of alcohols for scavenging hydroxyl radicals where ethanol exhibits the highest rate constant in contrast with other alcohols [50]. Alcohol radicals react with the oxygen atoms of the functional groups (epoxide, hydroxyl present on GO, or f-MWCNTs) and carbon radicals are formed. Thereafter, the carbon radicals combine with hydrogen radicals present in the system and after decarboxylation reaction $\mathrm{C}=\mathrm{C}$ bonds are formed in $\mathrm{G}$ MWCNTs.

3.3. Morphology. Morphology of the samples was studied with the help of SEM and TEM (Figures 5, 6, and 7).

The SEM image of GO (Figure 5(a)) is seen to consist of randomly aggregated wrinkled sheets closely associated with each other. This feature is in agreement with the TEM image of GO (Figure 5(c)). The SEM image of MWCNTs shows dense structure comprised of randomly aggregated tubules (Figure 5(b)).

The SEM images of G-MWCNT hybrids $(3: 1,1: 1$, and $1: 3$ ratios) are shown in Figure 6 (a1, a2), (b1, b2), and (c1, c2), respectively. As observed from the micrographs, the MWCNTs are seen to be incorporated into the graphene layers and the surface morphology exhibits a mixed structure with MWCNTs dispersed between different GO sheets. This can be due to the possible interactions between $\pi-\pi^{*}$ hydrophobic region of GO and the side walls of $\mathrm{f}-\mathrm{MWCNTs}$.

These interactions avoid stacking up of MWCNTs and keep the dispersion of G-MWCNTs stable for longer time (at least 8 months). However, $1: 1$ ratio (b1 and b2) shows uniform distribution of graphene layers and MWCNTs compared to that observed at other ratios. In case of $1: 3$ ratio (a1, a2) the GO sheets are seen to be covered by a very thin layer of MWCNTs, while, at 3:1 ratio $(\mathrm{cl}, \mathrm{c} 2)$, agglomeration of MWCNTs on GO nanosheets can be noted. These observations are confirmed from the TEM images (Figure 7) of GOMWCNTs 1:3 (a1, a2), 1:1 (b1, b2), and 1:3 (c1, c2) ratios.

3.4. Electrical Resistance. The electrical resistance of the samples was measured to evaluate the conductivity of the synthesized nanomaterials and also the connectivity of layers along the edges in case of G-MWCNTs; Figure S4 in Supplementary
Material available online at http://dx.doi.org/10.1155/2014/ 903872 shows the bar diagram of resistance versus sample (GO, f-MWCNTs, and G-MWCNTs 3:1, G-MWCNTs $1: 1$, and G-MWCNTs $1: 3$ ). It can be seen that GO shows the highest resistance $\left(6 \mathrm{k} \Omega \mathrm{cm}^{-1}\right)$ due to the presence of hydroxyl and carboxyl functional groups. But f-MWCNTs show significantly lower resistance $\left(0.52 \mathrm{k} \Omega \mathrm{cm}^{-1}\right)$ than GO. However, among the hybrid nanomaterials, the resistance of G-MWCNTs $1: 1$ is significantly lower $\left(\sim 0.006 \mathrm{k} \Omega \mathrm{cm}^{-1}\right)$ compared to the resistance of G-MWCNT $3: 1\left(3 \mathrm{k} \Omega \mathrm{cm}^{-1}\right)$. Resistance obtained for G-MWCNT 1:3( 0.004) is similar as for $1: 1$ ratio. These results reveal that G-MWCNTs $1: 1$ and $1: 3$ ratios are highly conducting in nature which is perhaps due to the strong coupling between graphene sheets and carbon nanotubes [27].

The results of all the above characterizations confirm the formation of new hybrid structure containing grapheme and MWCNTs.

3.5. Electrochemical Analysis. The electrochemical response of G-MWCNT hybrids (1:3, 1:1, and 3:1 ratios), GO, and $\mathrm{f}$ MWCNTs were investigated by using $\mathrm{K}_{3} \mathrm{Fe}(\mathrm{CN})_{6}$ as the redox system due to its sensitivity/insensitivity to the electronic properties, surface microstructure, and surface chemistry of carbon electrodes [51].

Figure 8(a) shows the electrochemical response of $\mathrm{K}_{3} \mathrm{Fe}$ $(\mathrm{CN})_{6}[5 \mathrm{mM}]$ and $\mathrm{KCl}[0.5 \mathrm{mM}]$ at GC bare, GO, fMWCNTs, G-MWCNTs $(3: 1)$, G-MWCNTs $(1: 1)$, and GMWCNTs (1:3) modified electrodes at a scan rate of $100 \mathrm{mVs}^{-1}$. The cyclic voltammogram of $\mathrm{K}_{3} \mathrm{Fe}(\mathrm{CN})_{6}$ is apparently improved at G-MWCNTs 1:1 and 1:3 ratios modified electrode, reflected by the enhancement in the peak currents $\left(i_{p}\right)$ and a decrease in the peak to peak potential $[\Delta \mathrm{Ep}]$ compared to that of GO modified electrode. These results signify that the electronic structure and the surface properties of G-MWCNTs modified electrode are advantageous for electron transfer $[51,52]$ which is attributed to the strong coupling between graphene sheets and carbon nanotubes [27]. Figure 8(b) depicts the amperometric responses for GC, GO, f-MWCNTs, and G-MWCNTs modified electrodes with successive addition of glucose concentrations (0.1-18 mM) 


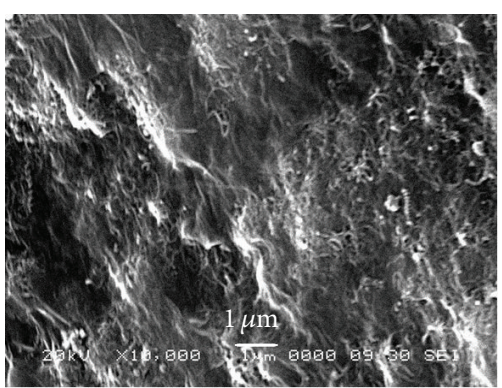

(a1)

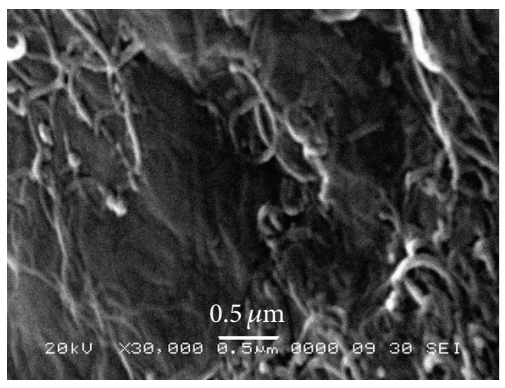

(a2)

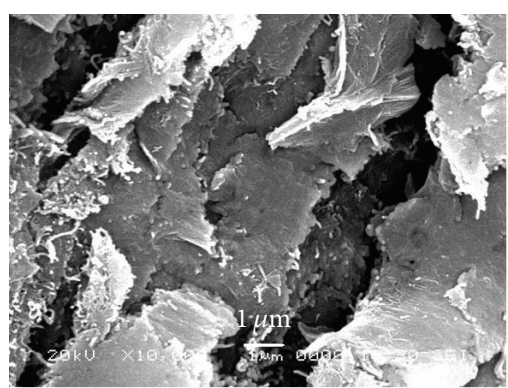

(b1)

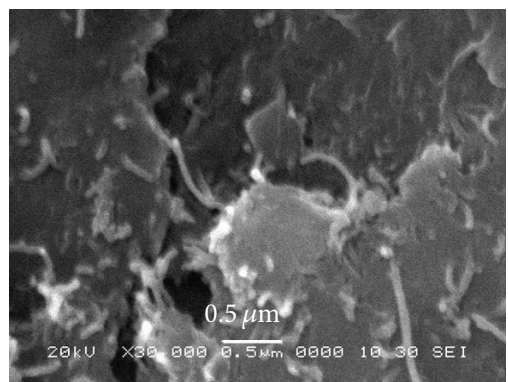

(b2)

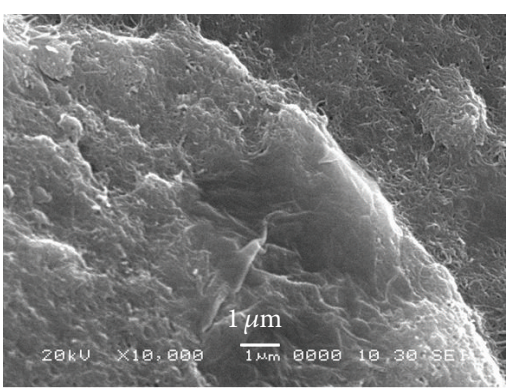

(c1)

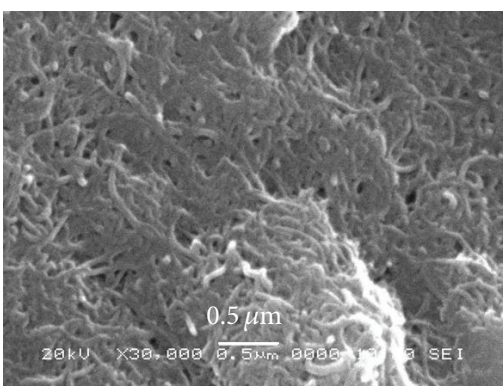

(c2)

Figure 6: SEM micrographs of G-MWCNTs $3: 1$ (a1, a2), G-MWCNTs 1:1 (b1, b2), and 1:3 (c1, c2), respectively.

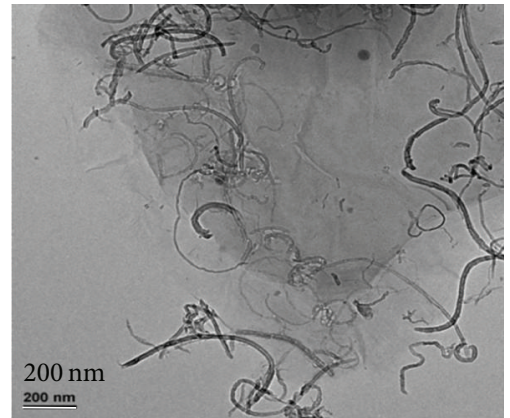

(a1)

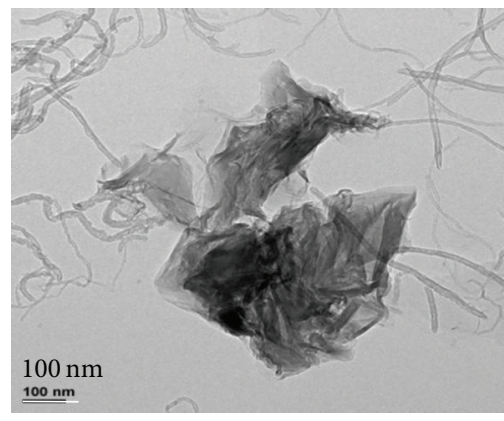

(a2)

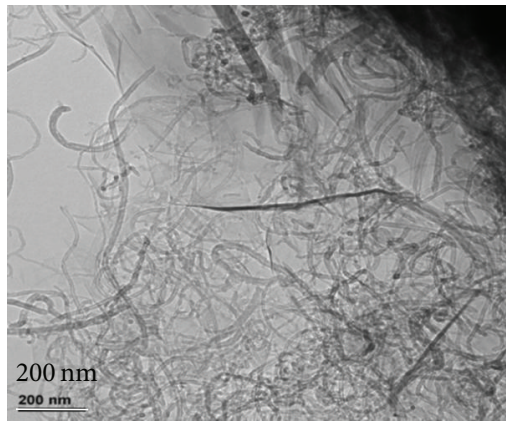

(b1)

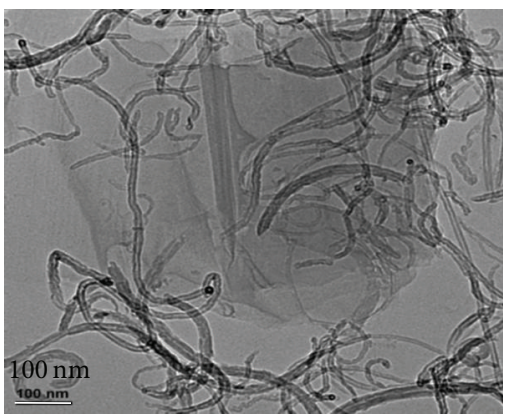

(b2)

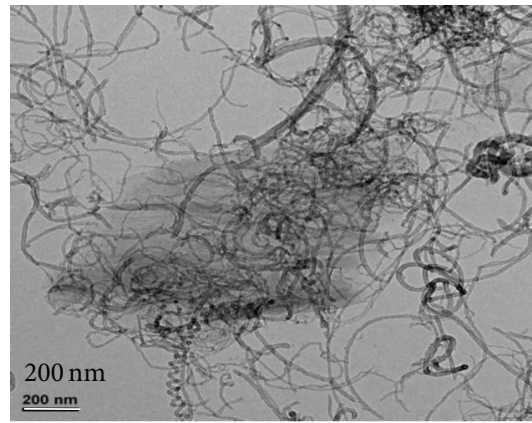

(c1)

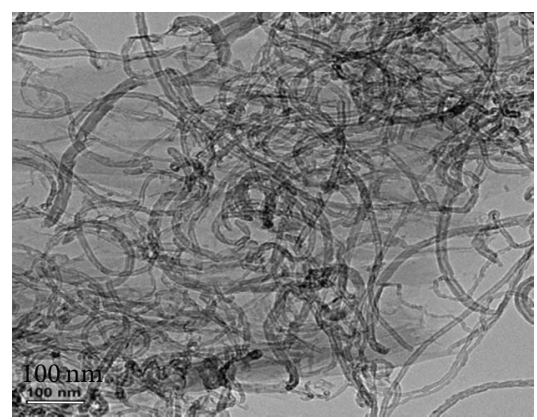

(c2)

Figure 7: TEM images of G-MWCNTs $3: 1$ (a1, a2), G-MWCNTs 1:1 (b1, b2), and 1:3 (c1, c2), respectively.

at an applied potential of $+0.6 \mathrm{~V}$ (S5) versus $\mathrm{Hg} / \mathrm{HgO}$ in $0.1 \mathrm{M} \mathrm{NaOH}$. The amperometric response of G-MWCNTs modified electrode exhibits a linear range $\left(R^{2}=0.985\right)$ from $0.1 \mathrm{mM}$ to $14 \mathrm{mM}(\mathrm{S} 6)$, with sensitivity and detection limit of $12.5 \mu \mathrm{AmM}^{-1} \mathrm{~cm}^{-2}$ and $1.45 \mu \mathrm{M}$, respectively (S7). The reproducibility of the sensor was determined by conducting 4 successive amperometric measurements of glucose using single G-MWCNTs modified electrode (S8). The relative standard deviations (R.S.D.) of the reproducible currents (S9) show that the electrode was not poisoned by the oxidation 


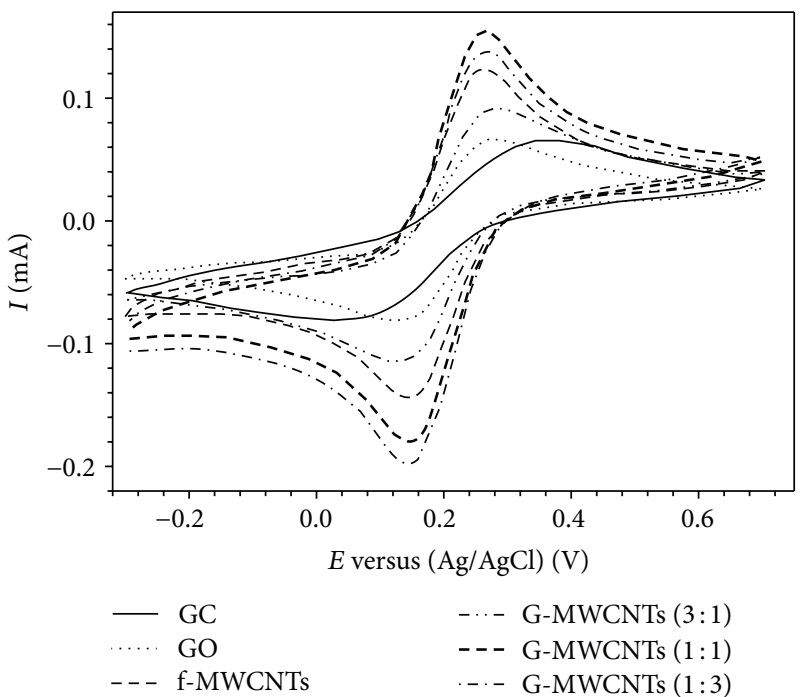

(a)

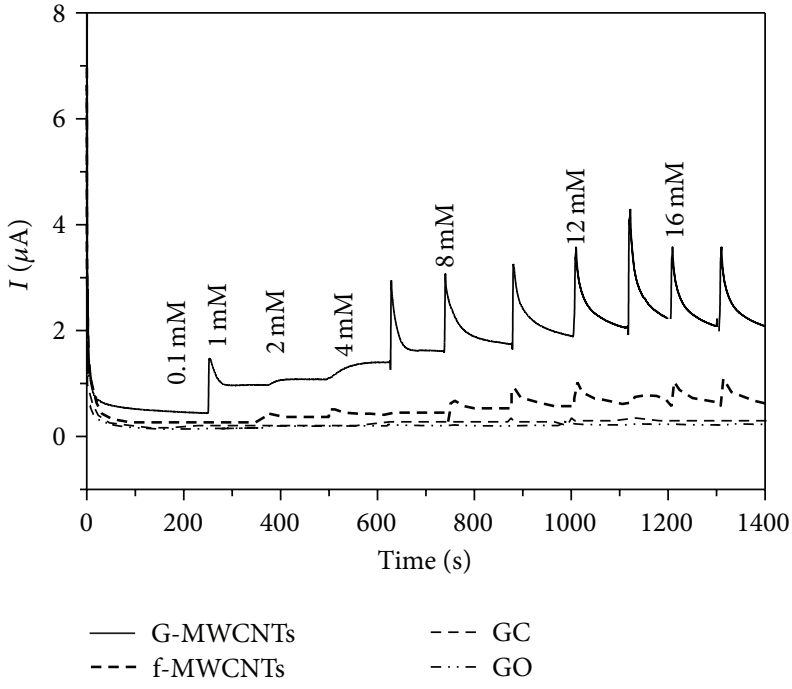

(b)

Figure 8: (a) CVs of bare GC electrode and that modified with GO, f-MWCNTs, G-MWCNTs (3:1), G-MWCNTs (1:1), and G-MWCNTs $(1: 3)$. The experiments were carried out in $5.0 \mathrm{mM} \mathrm{K}_{3}\left[\mathrm{Fe}(\mathrm{CN})_{6}\right]$ containing $1.0 \mathrm{M} \mathrm{KCl}$ and the potentials were applied versus $\mathrm{Ag} / \mathrm{AgCl}$ reference electrode at a scan rate of $100 \mathrm{mVs}^{-1}$. (b) Amperometric responses of GC, GO, f-MWCNTs, and G-MWCNTs modified electrodes for successive addition of glucose concentrations $(0.1-18 \mathrm{mM})$ at an applied potential of $+0.6 \mathrm{~V}$, versus $\mathrm{Hg} / \mathrm{HgO}$ in $0.1 \mathrm{M} \mathrm{NaOH}$.

products and is highly reproducible. Oxidizable species, such as ascorbic acid (AA) and uric acid (UA), usually coexist with glucose in biological fluids on different electrodes, particularly on nonenzymatic glucose sensors [53].

The normal physiological level of glucose is $3-8 \mathrm{mM}$, which is much higher than that of the interfering species, $\mathrm{AA}$, and $\mathrm{UA}(\sim 0.1 \mathrm{mM})$. However, electron transfer rates of the interfering species are highly greater than that of glucose. Consequently, their oxidation currents are comparable to that from highly concentrated glucose. Therefore, the amperometric responses of the modified electrode at $+0.6 \mathrm{~V}$ in solutions of $0.1 \mathrm{M} \mathrm{NaOH}$ for $0.1 \mathrm{mM}$ $\mathrm{UA}, 0.1 \mathrm{mM} \mathrm{AA}$, and $3 \mathrm{mM}$ glucose were evaluated. For a better comparison, the response current of $3 \mathrm{mM}$ glucose is set as $100 \%$, and the responses of the interfering species are normalized by this value. The current responses obtained for UA and AA were $\sim 0.10 \mu \mathrm{A}$ and $\sim 0.12 \mu \mathrm{A}, 8.06 \%$ and $9.60 \%$, respectively, which are significantly lower as compared to that of glucose $(\sim 1.24 \mu \mathrm{A})$ (S10). The results show that the interference from $\mathrm{UA}$ and $\mathrm{AA}$ is negligible.

These results indicate that the selectivity of G-MWCNTs is good enough to be used as a sensor for glucose. The batchto-batch reproducibility was estimated from the current responses of 6 different sensors toward $3.0 \mathrm{mM}$ glucose, and an RSD of $4.89 \%$ was obtained, indicative of the reliability of the proposed method. The long-term stability is also a significant parameter for evaluating the performance of the sensor. A response current of $3 \mathrm{mM}$ glucose was determined every two days. The results show that the response current is $\sim 75.30 \%$ of its initial value after 15 days (S11), which indicate that the stability of the sensor is good.

\section{Conclusion}

The $\gamma$-ray irradiation method appears to be a clean, simple, and cost-effective method to synthesize highly stable G-MWCNT hybrid nanomaterials. Characterization results proved that the G-MWCNT hybrid shows significant decrease in the self-aggregation and stacking of GO and MWCNTs due to appropriate coupling and interconnected network between MWCNTs and GO layers. This results in an increase in the stability, electrocatalytic activity, and electrical conductivity of hybrid nanomaterial compared to GO and MWCNTs individually. The amperometric sensor based on the G-MWCNTs modified electrode exhibits sensitivity of $12.5 \mu \mathrm{AmM}^{-1} \mathrm{~cm}^{-2}$ and low detection limit $1.45 \mu \mathrm{M}$, with a linear range from $0.1 \mathrm{mM}$ to $14 \mathrm{mM}\left(R^{2}=0.985\right)$ and negligible interference due to the presence of ascorbic acid and uric acid. These improvements in the properties of G-MWCNTs qualify it as an important material to develop electrical as well as electrochemical sensing devices. Therefore, it appears to be promising for the fabrication of sensors based on the GMWCNTs hybrid for other applications.

\section{Conflict of Interests}

The authors declare that there is no conflict of interests regarding the publication of this paper.

\section{Acknowledgments}

The financial supports provided by Department of Chemistry, University of Pune, and University of Tehran are gratefully appreciated. The authors acknowledge CNQS, Department 
of Physics, University of Pune, for XRD, SEM, and FTIR facilities and Professor Pavankumar, IISER, Pune, for Raman spectra.

\section{References}

[1] S. Park, J. W. Suk, J. An et al., "The effect of concentration of graphene nanoplatelets on mechanical and electrical properties of reduced graphene oxide papers," Carbon, vol. 50, no. 12, pp. 4573-4578, 2012.

[2] W. Wei and X. Qu, "Extraordinary physical properties of functionalized graphene," Small, vol. 8, no. 14, pp. 2138-2151, 2012.

[3] Y. Zhu, S. Murali, W. Cai et al., "Graphene and graphene oxide: synthesis, properties, and applications," Advanced Materials, vol. 22, no. 35, pp. 3906-3924, 2010.

[4] N. O. Weiss, H. Zhou, L. Liao et al., "Graphene: an emerging electronic material," Advanced Materials, vol. 24, no. 43, pp. 5782-5825, 2012.

[5] R. Ribeiro, J.-M. Poumirol, A. Cresti et al., "Unveiling the magnetic structure of graphene nanoribbons," Physical Review Letters, vol. 107, no. 8, Article ID 086601, 5 pages, 2011.

[6] G. Jo, M. Choe, S. Lee, W. Park, Y. H. Kahng, and T. Lee, “The application of graphene as electrodes in electrical and optical devices," Nanotechnology, vol. 23, no. 11, Article ID 112001, 20 pages, 2012.

[7] Q. Li, B. Guo, J. Yu et al., "Highly efficient visible-light-driven photocatalytic hydrogen production of CdS-cluster-decorated graphene nanosheets," Journal of the American Chemical Society, vol. 133, no. 28, pp. 10878-10884, 2011.

[8] W. Qian, R. Hao, J. Zhou et al., "Exfoliated graphene-supported $\mathrm{Pt}$ and Pt-based alloys as electrocatalysts for direct methanol fuel cells," Carbon, vol. 52, pp. 595-604, 2013.

[9] J. Yang and S. Gunasekaran, "Electrochemically reduced graphene oxide sheets for use in high performance supercapacitors," Carbon, vol. 51, no. 1, pp. 36-44, 2013.

[10] Y. Shao, J. Wang, H. Wu, J. Liu, I. A. Aksay, and Y. Lin, "Graphene based electrochemical sensors and biosensors: a review," Electroanalysis, vol. 22, no. 10, pp. 1027-1036, 2010.

[11] F. Liu, Y. Piao, K. S. Choi, and T. S. Seo, "Fabrication of free-standing graphene composite films as electrochemical biosensors," Carbon, vol. 50, no. 1, pp. 123-133, 2012.

[12] M. Segal, "Selling graphene by the ton," Nature Nanotechnology, vol. 4, no. 10, pp. 612-614, 2009.

[13] C. E. Banks, A. Crossley, C. Salter, S. J. Wilkins, and R. G. Compton, "Carbon nanotubes contain metal impurities which are responsible for the "electrocatalysis" seen at some nanotubemodified electrodes," Angewandte Chemie-International Edition, vol. 45, no. 16, pp. 2533-2537, 2006.

[14] G. I. Titelman, V. Gelman, S. Bron, R. L. Khalfin, Y. Cohen, and H. Bianco-Peled, "Characteristics and microstructure of aqueous colloidal dispersions of graphite oxide," Carbon, vol. 43, no. 3, pp. 641-649, 2005.

[15] H.-L. Guo, X.-F. Wang, Q.-Y. Qian, F.-B. Wang, and X.-H. Xia, "A green approach to the synthesis of graphene nanosheets," ACS Nano, vol. 3, no. 9, pp. 2653-2659, 2009.

[16] G.-H. Moon, Y. Park, W. Kim, and W. Choi, "Photochemical loading of metal nanoparticles on reduced graphene oxide sheets using phosphotungstate," Carbon, vol. 49, no. 11, pp. 3454-3462, 2011.
[17] W. Yang, K. R. Ratinac, S. R. Ringer, P. Thordarson, J. J. Gooding, and F. Braet, "Carbon nanomaterials in biosensors: should you use nanotubes or graphene," Angewandte ChemieInternational Edition, vol. 49, no. 12, pp. 2114-2138, 2010.

[18] Z. H. Ni, H. M. Wang, J. Kasim et al., "Graphene thickness determination using reflection and contrast spectroscopy," Nano Letters, vol. 7, no. 9, pp. 2758-2763, 2007.

[19] J. C. Meyer, A. K. Geim, M. I. Katsnelson, K. S. Novoselov, T. J. Booth, and S. Roth, "The structure of suspended graphene sheets," Nature, vol. 446, no. 7131, pp. 60-63, 2007.

[20] J. J. Gooding, A. Chou, J. Liu, D. Losic, J. G. Shapter, and D. B. Hibbert, "The effects of the lengths and orientations of singlewalled carbon nanotubes on the electrochemistry of nanotubemodified electrodes," Electrochemistry Communications, vol. 9, no. 7, pp. 1677-1683, 2007.

[21] P. Avouris, Z. Chen, and V. Perebeinos, "Carbon-based electronics," Nature Nanotechnology, vol. 2, no. 10, pp. 605-615, 2007.

[22] M. Pumera, "Carbon nanotubes contain residual metal catalyst nanoparticles even after washing with nitric acid at elevated temperature because these metal nanoparticles are sheathed by several graphene sheets," Langmuir, vol. 23, no. 11, pp. 64536458, 2007.

[23] C. P. Jones, K. Jurkschat, A. Crossley, R. G. Compton, B. L. Riehl, and C. E. Banks, "Use of high-purity metal-catalyst-free multiwalled carbon nanotubes to avoid potential experimental misinterpretations," Langmuir, vol. 23, no. 18, pp. 9501-9504, 2007.

[24] K. Gong, S. Chakrabarti, and L. Dai, "Electrochemistry at carbon nanotube electrodes: is the nanotube tip more active than the sidewall?" Angewandte Chemie-International Edition, vol. 47, no. 29, pp. 5446-5450, 2008.

[25] M.-Y. Yen, M.-C. Hsiao, S.-H. Liao et al., "Preparation of graphene/multi-walled carbon nanotube hybrid and its use as photoanodes of dye-sensitized solar cells," Carbon, vol. 49, no. 11, pp. 3597-3606, 2011.

[26] Z. Fan, J. Yan, L. Zhi et al., "A three-dimensional carbon nanotube/graphene sandwich and its application as electrode in supercapacitors," Advanced Materials, vol. 22, no. 33, pp. 37233728, 2010.

[27] Y.-S. Kim, K. Kumar, F. T. Fisher, and E.-H. Yang, "Out-of-plane growth of CNTs on graphene for supercapacitor applications," Nanotechnology, vol. 23, no. 1, Article ID 015301, 7 pages, 2012.

[28] S. Wooa, Y. R. Kima, T. D. Chunga, Y. Piaob, and H. Kimc, "Synthesis of a graphene-carbon nanotube composite and its electrochemical sensing of hydrogen peroxide," Electrochim Acta, vol. 59, pp. 509-514, 2012.

[29] V. Mani, B. Devadas, and S.-M. Chen, "Direct electrochemistry of glucose oxidase at electrochemically reduced graphene oxide-multiwalled carbon nanotubes hybrid material modified electrode for glucose biosensor," Biosensors and Bioelectronics, vol. 41, no. 1, pp. 309-315, 2013.

[30] S. Das, R. Seelaboyina, V. Verma et al., "Synthesis and characterization of self-organized multilayered graphene-carbon nanotube hybrid films," Journal of Materials Chemistry, vol. 21, no. 20, pp. 7289-7295, 2011.

[31] X. Dong, B. Li, A. Wei et al., "One-step growth of graphenecarbon nanotube hybrid materials by chemical vapor deposition," Carbon, vol. 49, no. 9, pp. 2944-2949, 2011.

[32] X. Dong, G. Xing, M. B. Chan-Park et al., "The formation of a carbon nanotube-graphene oxide core-shell structure and its possible applications," Carbon, vol. 49, no. 15, pp. 5071-5078, 2011. 
[33] A. Henglein and D. Meisel, "Radiolytic control of the size of colloidal gold nanoparticles," Langmuir, vol. 14, no. 26, pp. 7392-7396, 1998.

[34] N. P. Bayramgil, "Synthesis, characterization and drug release behavior of poly(1-vinyl 1,2,4-triazole) hydrogels prepared by gamma irradiation," Colloids and Surfaces B, vol. 97, pp. 182-189, 2012.

[35] J. V. Rojas and C. H. Castano, "Production of palladium nanoparticles supported on multiwalled carbon nanotubes by gamma irradiation," Radiation Physics and Chemistry, vol. 81, no. 1, pp. 16-21, 2012.

[36] K. Krishnamoorthy, R. Mohan, and S.-J. Kim, "Graphene oxide as a photocatalytic material," Applied Physics Letters, vol. 98, no. 24, Article ID 244101, 3 pages, 2011.

[37] C. Zhu, S. Guo, Y. Fang, and S. Dong, "Reducing sugar: new functional molecules for the green synthesis of graphene nanosheets," ACS Nano, vol. 4, no. 4, pp. 2429-2437, 2010.

[38] K. S. Vasu, B. Chakraborty, S. Sampath, and A. K. Sood, "Probing top-gated field effect transistor of reduced graphene oxide monolayer made by dielectrophoresis," Solid State Communications, vol. 150, no. 29-30, pp. 1295-1298, 2010.

[39] K. Krishnamoorthy, M. Veerapandian, R. Mohan, and S.-J. Kim, "Investigation of Raman and photoluminescence studies of reduced graphene oxide sheets," Applied Physics A, vol. 106, no. 3, pp. 501-506, 2012.

[40] Z. Xu, N. Gao, and S. Dong, "Preparation and layer-bylayer self-assembly of positively charged multiwall carbon nanotubes," Talanta, vol. 68, no. 3, pp. 753-758, 2006.

[41] S. J. Henley, R. A. Hatton, G. Y. Chen et al., "Enhancement of polymer luminescence by excitation-energy transfer from multi-walled carbon nanotubes," Small, vol. 3, no. 11, pp. 19271933, 2007.

[42] W. Qian, J. Chen, L. Wei, L. Wu, and Q. Chen, "Gamma-ray irradiation-induced improvement of hydrogen adsorption in multi-walled carbon nanotubes," Nano, vol. 4, no. 1, pp. 7-11, 2009.

[43] J. Shang, L. Ma, J. Li, W. Ai, T. Yu, and G. G. Gurzadyan, “The origin of fluorescence from graphene oxide," Scientific Reports, vol. 2, pp. 792-800, 2012.

[44] Y. Lin, B. Zhou, R. B. Martin et al., "Visible luminescence of carbon nanotubes and dependence on functionalization," Journal of Physical Chemistry B, vol. 109, no. 31, pp. 14779-14782, 2005.

[45] Q. Zhang, Y. Zhang, Z. Gao et al., "A facile synthesis of platinum nanoparticle decorated graphene by one-step $\gamma$-ray induced reduction for high rate supercapacitors," Journal of Materials Chemistry C, vol. 1, no. 2, pp. 321-328, 2013.

[46] L. Zhang, J. Liang, Y. Huang, Y. Ma, Y. Wang, and Y. Chen, "Sizecontrolled synthesis of graphene oxide sheets on a large scale using chemical exfoliation," Carbon, vol. 47, no. 14, pp. 33653368, 2009.

[47] G. Eda and M. Chhowalla, "Chemically derived graphene oxide: towards large-area thin-film electronics and optoelectronics," Advanced Materials, vol. 22, no. 22, pp. 2392-2415, 2010.

[48] H. Wang, J. T. Robinson, X. Li, and H. Dai, "Solvothermal reduction of chemically exfoliated graphene sheets," Journal of the American Chemical Society, vol. 131, no. 29, pp. 9910-9911, 2009.

[49] J. Belloni, M. Mostafavi, H. Remita, J.-L. Marignier, and M.-O. Delcourt, "Radiation-induced synthesis of mono- and multimetallic clusters and nanocolloids," New Journal of Chemistry, vol. 22, no. 11, pp. 1239-1255, 1998.
[50] E. Janata, "Direct optical observation of the formation of some aliphatic alcohol radicals. A pulse radiolysis study," Proceedings of the Indian Academy of Sciences, vol. 114, no. 6, pp. 731-737, 2002.

[51] W.-J. Lin, C.-S. Liao, J.-H. Jhang, and Y.-C. Tsai, "Graphene modified basal and edge plane pyrolytic graphite electrodes for electrocatalytic oxidation of hydrogen peroxide and $\beta$ nicotinamide adenine dinucleotide," Electrochemistry Communications, vol. 11, no. 11, pp. 2153-2156, 2009.

[52] R. L. McCreery, "Advanced carbon electrode materials for molecular electrochemistry," Chemical Reviews, vol. 108, no. 7, pp. 2646-2687, 2008.

[53] L. Tang, Y. Wang, Y. Li, H. Feng, J. Lu, and J. Li, "Preparation, structure, and electrochemical properties of reduced graphene sheet films," Advanced Functional Materials, vol. 19, no. 17, pp. 2782-2789, 2009. 

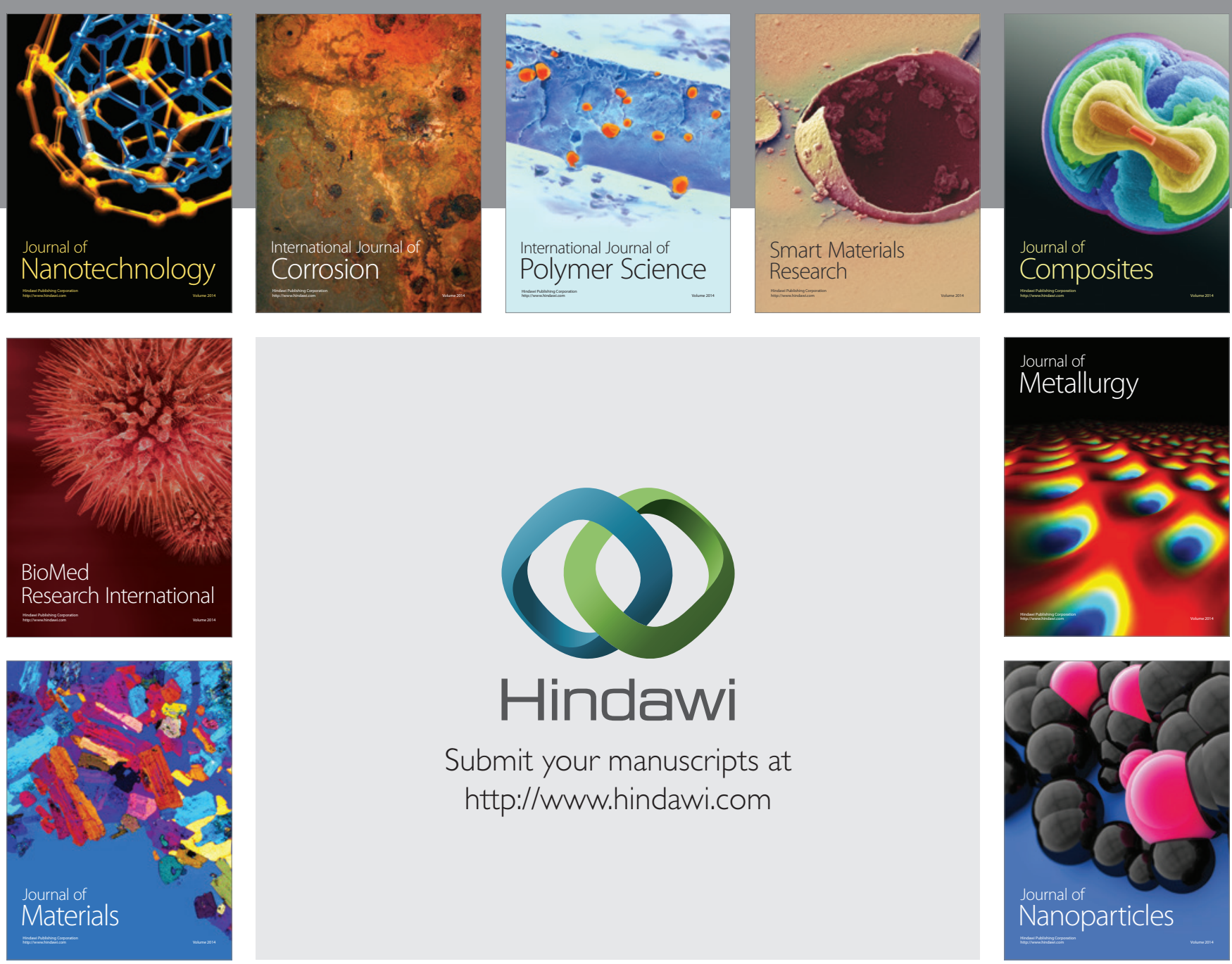

Submit your manuscripts at http://www.hindawi.com
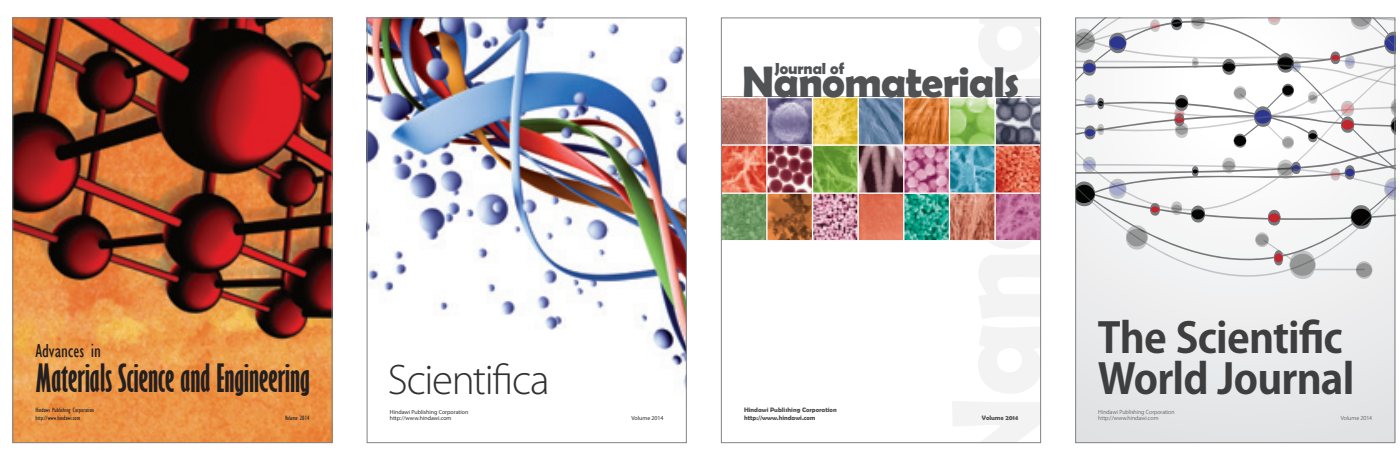

\section{The Scientific World Journal}
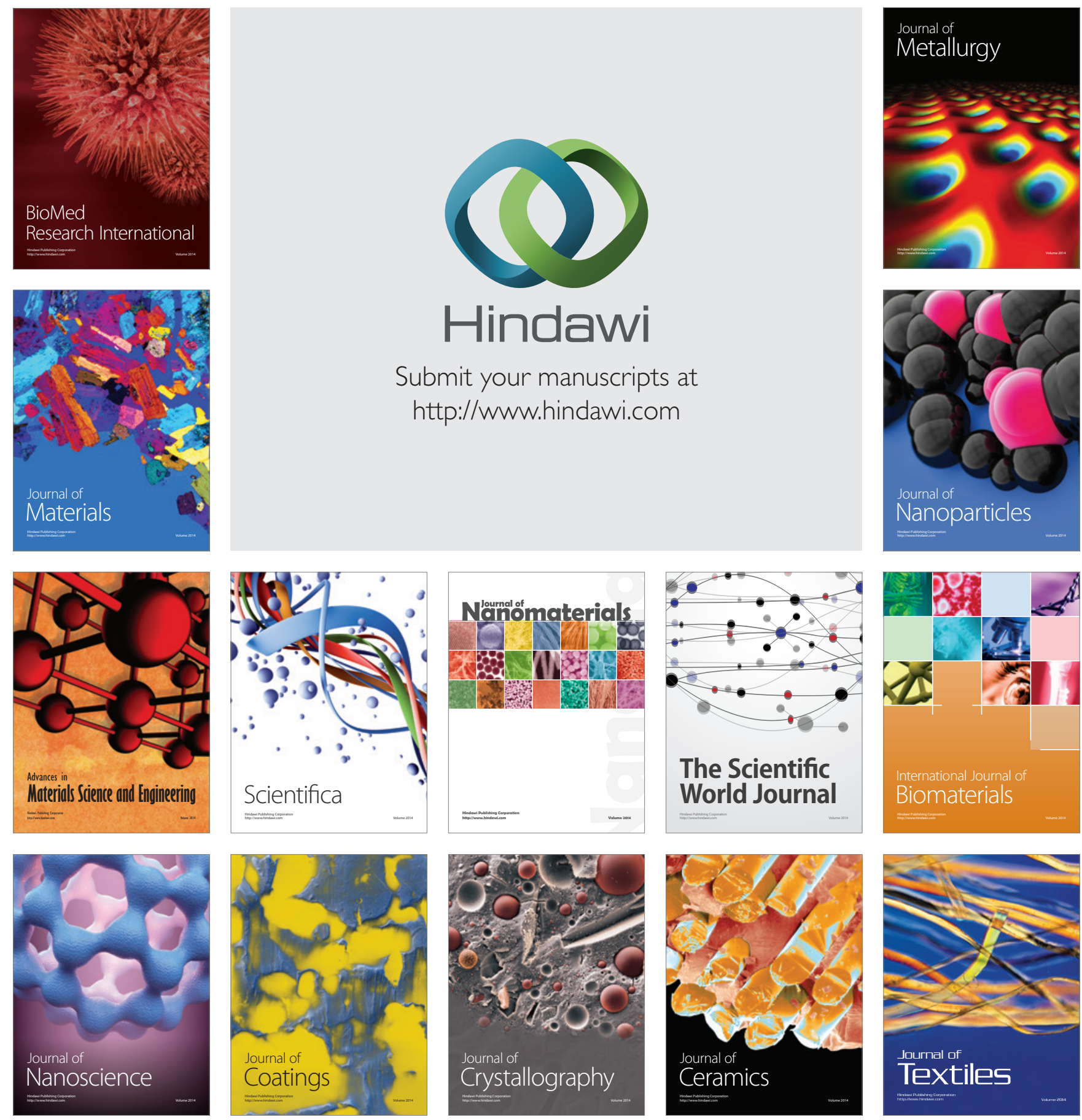